\title{
POBREZA SOB A ÓTICA MULTIDIMENSIONAL NO ESTADO DA BAHIA, BRASIL: UMA ANÁLISE DO RURAL E URBANO
}

Camilla Rusciolelli Barbosa

Universidade Federal da Bahia, doutoranda do Núcleo de Pós-Graduação em Administração - NPGA, Salvador,

Bahia, Brasil.

camillarb@hotmail.com

Monick Midlej do Espírito Santo

Universidade Estadual de Santa Cruz, Programa de Pós-Graduação em Economia Regional e Políticas Públicas, Ilhéus, Bahia, Brasil. mmesanto@uesc.br

Andréa da Silva Gomes Universidade Estadual de Santa Cruz, professora plena do departamento de Ciências Econômicas, Ilhéus, Bahia, Brasil. andreauesc@gmail.com

Universidade Estadual de Santa Cruz professora plena do Mônica de Moura Pires

Brasil

mpires@uesc.br

Fernanda Calasans Costa Lacerda Pessoti Universidade Federal da Bahia, doutoranda em Economia, Salvador, Bahia, Brasil. fecalasans@gmail.com

\begin{abstract}
RESUMO
A abordagem da pobreza possui caráter dinâmico, sendo crescente as discussões entre a adoção da abordagem unidimensional ou multidimensional para defini-la e mensurá-la. Este trabalho se propõe a mensurar a pobreza rural e urbana sob a perspectiva multidimensional no estado da Bahia, Brasil, com base em dados sobre a população desse estado. Discutiram-se as principais abordagens sobre essa temática, seguido pela mensurabilidade da pobreza através da aplicação do Índice de Pobreza Multidimensional (IPM) proposto por Alkire e Foster (2007). O índice é composto por dez indicadores distribuídos em três dimensões igualmente ponderadas: educação, saúde e padrão de vida. A maior parcela de indivíduos privados tanto na área rural quanto urbana foram os referentes aos indicadores tempo de escolaridade, saneamento e coleta de lixo. Os resultados apontaram maior intensidade e incidência da pobreza multidimensional na área rural da Bahia, justificando a necessidade de maior investigação dos atributos nesse meio.
\end{abstract}

Palavras-chave: Pobreza multidimensional. IPM. Disparidades regionais. Intensidade. Incidência.

\section{POVERTY UNDER THE MULTIDIMENSIONAL OPTICS IN THE STATE OF BAHIA, BRAZIL: AN ANALYSIS OF RURAL AND URBAN}

\begin{abstract}
The approach to poverty has a dynamic character, and there is a growing debate between adopting the one-dimensional or multidimensional approach to define and measure it. This paper aims to measure rural and urban poverty from a multidimensional perspective in the state of Bahia, Brazil, based on population data in that state. The main approaches on this topic were discussed, followed by the measurability of poverty through the application of the multidimensional poverty index (MPI) proposed by Alkire and Foster (2007). The index is composed of ten indicators distributed in three equally weighted dimensions: education, health and standard of living. The largest proportion of private individuals in both rural and urban areas were those referring to the indicators schooling time, sanitation and garbage collection. The results indicated a higher intensity and incidence of multidimensional poverty in rural Bahia, justifying the need for further investigation of the attributes in this area
\end{abstract}

Keywords: Multidimensional poverty. MPI. Regional disparities. Intensity. Incidence. 


\section{INTRODUÇÃO}

Os estudos recentes sobre pobreza destacam-se por incorporar a multidimensionalidade das privações entre os parâmetros de mensuração, compreendendo a interligação de diferentes fatores que influenciam no seu surgimento e permanência. Entretanto, a associação entre pobreza e insuficiência de renda ainda é bastante disseminada, haja vista que a perspectiva unidimensional dominou esse campo por um longo período, tanto pelo fato dos rendimentos determinarem a capacidade de consumo e acesso aos bens, quanto pela simplificação metodológica proporcionada por esse enfoque.

Dessa forma, a pobreza unidimensional é identificada e mensurada com base na insuficiência de recursos financeiros diante de um dado ponto de referência definido como linha de pobreza. É, portanto, calcada na renda, requer uma estimação de linha de pobreza, busca captar heterogeneidades a partir dos rendimentos e sofre forte influência da microeconomia e dos conceitos neoclássicos de utilidade (WAQUIL e MATTOS, 2002).

Em contraponto, Amartya Sen, que tornou holística a discussão sobre desenvolvimento humano e bem-estar e foi um dos precursores das abordagens multidimensionais acerca da pobreza, assevera que apesar do bem-estar de um indivíduo ter uma relação direta com a capacidade de consumo que ele dispõe, existem oportunidades de escolhas que ultrapassam o poder aquisitivo, quais sejam as características individuais e sociais, por exemplo (SEN, 2001).

Com isso o autor indica que a definição da pobreza está relacionada à privação das capacidades básicas de um indivíduo, e não simplesmente por ocupar um nível inferior à linha de pobreza préestabelecida. Para ele, a capacidade (capability) refere-se à liberdade substantiva de atingir combinações alternativas de funcionamento, possibilitando ao indivíduo optar por estilos de vida que mais the agrade, sem ser necessariamente imposto a tal.

Isso posto, objetiva-se mensurar a pobreza para os municípios do Estado da Bahia, situado no Nordeste brasileiro, com uma área aproximadamente $564 \mathrm{mil} \mathrm{km}^{2}$ (IBGE,s/d), sob o prisma multidimensional a partir da metodologia do IPM - Índice de Pobreza Multidimensional desenvolvido por Alkire e Foster (2007) e adotado pela ONU tendo como base três dimensões: saúde, educação e padrão de vida. Salienta-se que uma proposição desse índice consiste em refletir os aspectos primordiais selecionados pela Organização das Nações Unidas (ONU) como Objetivos do Milênio (ODM), estabelecidos em 2000.

O presente artigo se propõe, ainda, a examinar a trajetória dos estudos científicos acerca da pobreza, desde o seu prisma unidimensional até o âmbito da multidimensionalidade, evidenciando seu caráter evolutivo. Com essa finalidade, os conceitos e princípios que norteiam este estudo organizam-se em volta de uma abordagem cronológica sobre o assunto no contexto mundial, seguido pela discussão de diagnósticos produzidos sobre o tema no Brasil e na Bahia.

\section{REVISÃO DE LITERATURA}

\section{EVOLUÇÃO CONCEITUAL DA POBREZA}

As primeiras formulações relacionadas ao estudo da pobreza estavam ligadas a subsistência, originadas na implementação das Poor Laws, em que a sobrevivência dos indivíduos era medida pela quantidade de pão, farinha de pão ou dinheiro equivalente, necessários à provisão física mínima estabelecida por estudos nutricionais da época (LIMA, 2005).

Pelo menos até a década de 1970 os problemas sociais estavam geralmente atrelados à dependência do crescimento econômico, com isso, acreditava-se que o aumento na produção de riquezas ocasionaria a automática distribuição de renda (SANTOS, 2009). Essa associação provocou uma ligação direta entre a pobreza e a insuficiência de renda, disseminando a característica unidimensional da definição e dos estudos relacionados ao assunto. O cerne dessa abordagem considera pobre a parcela que não possui rendimentos suficientes para sobreviver adequadamente em sociedade. 
Segundo a abordagem unidimensional caracterizada pela renda, utilizada por Rocha (2006), é considerada pobre a parcela da populacão que não possui rendimento suficiente para atender as necessidades básicas de habitação, saúde, educação, alimentação, entre outras, por terem uma baixa renda familiar per capita. Já os que são considerados indigentes, possuem renda familiar per capita insuficiente para o atendimento apenas da alimentação, a mais básica das necessidades. Esse tipo de abordagem considerando a renda como critério destaca-se diante da economia monetizada do Brasil, somado a disponibilidade de dados estatísticos para estimação de renda mínima necessária à sobrevivência dos indivíduos e identificação daqueles que não a atingem (ROCHA, 2003).

Rocha (2003) considera o estabelecimento da linha de pobreza uma maneira de operacionalizar a mensuração desse fenômeno, considerando para isso os recursos monetários que satisfaçam determinadas necessidades de consumo. Define-se um parâmetro de renda para aquisição de bens e serviços básicos, considerando como pobres aqueles que possuem renda inferior a esse limite estabelecido.

Lacerda (2009) salienta a existência de questionamentos acerca da definição de valor da linha de pobreza, as opiniões dos que adotam esse recurso tem sido divergentes, de modo que uns optam pela utilização de uma linha de pobreza absoluta pautada no suprimento das necessidades mínimas à sobrevivência, enquanto outros argumentam a favor do uso de uma linha de pobreza relativa que levem em consideração as condições de vida preponderante na sociedade em estudo, ambas as abordagens de cunho macroeconômico. Há ainda uma discussão quanto à existência de certa arbitrariedade na definição da linha de pobreza (ALKIRE e SANTOS, 2010; HOFFMANN, 2013).

A concepção de pobreza integrada aos baixos rendimentos que refletem condições de vida e de consumo inadequados tem sua ideia de adequação relacionada ao grau de riqueza do país, relativizando dessa forma o conceito de pobreza. Essa definição comparativa entre pobres e ricos, indica uma semelhança com o conceito de desigualdade econômica.

Apesar da difusão dos aspectos multidimensionais da pobreza no meio científico, ainda é recorrente considerações da insuficiência de renda como característica determinante para a pobreza. Isso pode ser explicado inicialmente através do seu caráter escalar, e também pelo fato de que a possibilidade de acesso aos bens de consumo é proporcionada por meio de recursos monetários (BARROS et al., 2006).

A partir de 1970 a conotação da pobreza passa a abranger o enfoque das necessidades básicas, incluindo em seu espectro a conveniência de se dispor de saneamento básico, água potável, educação, saúde e cultura. Esse novo enfoque representou um alargamento da concepção de sobrevivência física e começou a ser utilizado por órgãos ligados a Organização das Nações Unidas (CRESPO e GUROVITZ, 2002).

Nesse sentido se deu a introdução do prisma das necessidades básicas, que admitia outros fatores responsáveis pelas privações que ultrapassavam a dieta básica, e inseriam na composição das necessidades humanas vários atributos. O enfoque da abordagem das necessidades básicas está mais direcionado a identificação dos sintomas da privação do que com a sua extensão, sendo responsável por introduzir as múltiplas dimensões a investigação da pobreza e do desenvolvimento, de modo que indubitavelmente representa um avanço nos estudos acerca dos temas.

Essa abordagem associa a pobreza diretamente a não satisfação de necessidades humanas específicas, com base em critérios multidimensionais. A perspectiva das necessidades básicas relaciona-se com o conceito de funcionamentos (functioning's) desenvolvido por Sen (2010), o qual considera como reflexo das diversas coisas que o indivíduo avalie pertinente fazer ou ter.

Sob esse enfoque, os funcionamentos podem ser considerados componentes característicos de bemestar, de modo que as pessoas possuidoras dos maiores níveis de funcionamentos são vistas como as que vivem bem. Por outro lado, as necessidades básicas correspondem ao caminho cujos indivíduos dispõem para atingir funcionamentos, tendo sua especificação atrelada às peculiaridades de cada um.

Rocha (2003), por sua vez, relaciona as necessidades básicas com a sobrevivência física, admitindo que a sua abordagem possa aderir à noção de pobreza relativa. Isso porque, é preciso ponderar as especificidades de cada contexto social e as peculiaridades de cada lugar. Na tentativa de dispor de um indicador social sintético que refletisse as basic needs, foram desenvolvidas medidas como Índice de Desenvolvimento Humano (IDH) e posteriormente o Índice de Pobreza Humana (IPH). Essas medidas somadas à ampliação das teorias cooperaram com o surgimento de um novo enfoque, a abordagem das capacitações. 
A perspectiva conceitual da pobreza apresentou avanços em sua construção a partir das formulações desenvolvidas por Amartya Sen que descreveu as facetas da pobreza e se questionou o porquê ela existe, como medi-la, quem são os pobres e porquê eles existem, entendendo que a superação dos problemas vividos é essencial para a processo de desenvolvimento (SEN, 2010).

Ou seja, a complexidade da pobreza se relaciona diretamente com o desenvolvimento e, consequentemente, com a liberdade do indivíduo (SEN, 2010), na qual esta é uma ação condicionada pelas oportunidades sociais, políticas e econômicas. Assim, é imperativo atentar-se as integrações entre as oportunidades econômicas, liberdades políticas, serviços sociais, segurança protetora, entre muitas outras.

Assim, para que haja o desenvolvimento, é necessária a remoção das principais fontes de privação de liberdade, são elas: "pobreza e tirania, carência de oportunidades econômicas e destituição social sistemática, negligência dos serviços públicos e intolerância ou interferência excessiva de Estados repressivos" (SEN, 2010, p. 18).

A abordagem das capacitações caracteriza-se por inserir a multidimensionalidade no contexto de análise da pobreza, visando identificar as causas e formas de dirimir as múltiplas carências existentes, além de prezar pela objetividade com o propósito de evitar resultados tendenciosos e conclusões subjetivas. Tal entendimento permite que a análise da pobreza tenha sua natureza melhor compreendida através da ótica das capacidades, pois dessa maneira é possível identificar as causas das privações, sem apegar-se exclusivamente aos "meios" - normalmente a associação entre pobreza e renda. Preocupa-se, portanto, com as finalidades que as pessoas almejam e podem alcançar e as liberdades necessárias para tal. A importância dessa abordagem reside no fato de que as privações são vistas em um nível que se aproxima das demandas de justiça social (SEN, 2010).

Cabe ressaltar que a perspectiva das capacitações não refuta a associação entre renda e pobreza, apenas apresenta elementos complementares e de fundamental importância à sobrevivência humana, que não podem ser excluídos dos critérios de análise. Nesse sentido, Laderchi et al. (2006) argumentam que os modos de enxergar as privações direcionam as ações no contexto das políticas públicas de combate à pobreza, ou seja, enquanto uma abordagem unidimensional pautada nos rendimentos sugere o foco no crescimento econômico ou na redistribuição de renda, a abordagem das capacidades enfatiza a necessidade de ampliação dos serviços públicos.

Finalmente, conforme observado por Sen (2010), avaliar a pobreza exige a resolução de questões como a identificação das pessoas consideradas pobres - por meio da delimitação de uma linha de pobreza, além da abrangência desses atributos em um indicador que possibilite compará-la.

Em termos regionais, considerando a área de estudo proposta, a observação e análise da pobreza podem ocorrer através dos índices e indicadores uni ou multidimensionais, como o IDH que, na Bahia, retrata os baixos níveis de educação do estado em relação à média nacional e demais Unidades da Federação (PNUD, IPEA, FJP, 2010).

Os indícios de precariedade do ensino do estado são vistos diante da falta de infraestrutura física adequada em algumas escolas públicas até a ausência de incentivos aos profissionais que atuam nessa área, com remuneração pouco satisfatória em comparação a outras carreiras. Com a pretensão de amenizar essa situação vivenciada em todo o país, iniciativas recentes implementadas em meados da década de 1990 buscaram promover o aumento dos investimentos na educação básica, a exemplo da criação do Fundo de Manutenção e Desenvolvimento do Ensino Fundamental e de Valorização do Magistério (FUNDEF) - substituído em 2006 pelo FUNDEB - objetivando alcançar a "universalização, a manutenção e a melhoria qualitativa desse nível de ensino" (MEC, 2014).

No quesito saúde, um dos grandes avanços possibilitados a partir da Constituição de 1988 consistiu na universalização do seu direito, seguido pela promulgação da Lei Federal nº 8.080/90, que dispõe sobre as condições para a promoção, proteção e recuperação da saúde, a organização e o funcionamento dos serviços correspondentes, lei que institucionaliza o SUS - Sistema Ủnico de Saúde.

Apesar de dispor de atendimento à saúde gratuito, grande parcela da população não tem acesso a esse direito social, entre outros, devido à superlotação dos hospitais, falta de profissionais da área, distância física dos principais centros hospitalares que impedem esse alcance. Ainda assim, indicadores que visam refletir, de maneira geral, as condições de desenvolvimento socioeconômico e infraestrutura ambiental, bem como o acesso e a qualidade dos recursos disponíveis para atenção à saúde vem apresentando melhorias. 
A captação da real situação do setor de saúde no estado da Bahia é altamente complexa e este trabalho reconhece a limitação de utilizar variáveis relacionados à mortalidade infantil e capacidade de nutrição que, embora possuam extrema importância, não podem ser assumidas como representação absoluta da conjuntura da saúde baiana.

É válido salientar que um levantamento realizado pela REDE (2002) constatou uma tendência de redução da mortalidade infantil em todas as regiões do país, indicando progresso nas condições de vida, queda na taxa de fecundidade e as reações à interferência de políticas públicas relacionadas à saúde. No entanto, o Nordeste continuou a apresentar valores médios mais elevados, em comparação às demais regiões do Brasil.

Em que pesem as limitações quanto à utilização da proxy, a fome e a desnutrição retratam a face mais cruel das privações, a alimentação é a mais básica das necessidades e, portanto, não poderia ser suprimida dessa análise. Complementarmente, Sen (2010) argumenta que a privação das liberdades habitualmente tem relação direta com a insuficiência de renda, por tirar das pessoas a liberdade de alimentar-se adequadamente, por exemplo. Assim, observou-se que o percentual de privações na Bahia nesse quesito foi de 3,96\%, com níveis mais elevados para o âmbito rural do que para o urbano.

Em um período recente, é reduzida a parcela da população que não tem acesso à alimentação básica a e essa condição está relacionada à valorização do salário mínimo e ao aumento da destinação de recursos públicos à transferência de renda direta, cujo principal expoente refere-se ao Programa Bolsa Família (PBF). Segundo Jannuzzi e Pinto (2013), os gastos com políticas sociais no Brasil cresceram de $13 \%$ do PIB em 1980 para aproximadamente $25 \%$ em 2013.

A estratégia para distribuição desses recursos consiste em priorizar as famílias em situação de maior vulnerabilidade, focando nas regiões de maior pobreza. Assim, Hoffmann (2013) sinaliza que no período entre 2001 e 2011 as transferências do governo federal possibilitaram uma redução na desigualdade de renda do país entre $15 \%$ e $20 \%$. Dessa forma vem sendo observada a consequente diminuição da desnutrição e da insegurança alimentar e nutricional.

Apesar das recentes iniciativas com vistas à redução da pobreza e desigualdade, o Brasil, sobretudo os estados da região Nordeste, ainda enfrenta desafios diários, e algumas das privações dos indivíduos pode ser observada, ainda que de forma abstrata, neste trabalho que visou fomentar a discussão de cunho tão relevante.

\section{METODOLOGIA}

\section{O ÍNDICE MULTIDIMENSIONAL DE POBREZA}

Para mensurar o IPM optou-se pela utilização do índice desenvolvido pela Universidade de Oxford a partir da metodologia de Alkire e Foster (2007). O IPM visa complementar as medidas unidimensionais, refletindo os aspectos das múltiplas privações em três dimensões: educação, saúde e padrão de vida (OPHI, s/d a). Cada dimensão corresponde a um terço, e cada indicador em cada dimensão é igualmente ponderado.

Esse índice pretende mensurar a incidência da pobreza, a sua intensidade e a sua composição nos diferentes países, estados, grupos étnicos, áreas rurais ou urbanas. Desenvolvido com o intuito de se tornar uma ferramenta para comparação entre as nações, admite-se a adaptação dos indicadores de acordo com a realidade de cada país, de modo a refletir suas reais especificidades, fatores que justificam a escolha por esse índice em detrimento dos outros.

Com relação à execução da metodologia proposta por Alkire e Foster, a OPHI (s/d b) sugere que sua aplicabilidade siga 12 passos (Figura 1). Inicialmente escolhe-se a unidade de análise, seguida pela escolha das dimensões a serem observadas e dos indicadores (etapas 1, 2 e 3). Deve-se considerar, entre outros fatores, a disponibilidade de dados e a relevância das informações disponíveis. Posteriormente são definidas as linhas de pobreza cujo corte é determinado por indicador (etapa 4), em sequência essas linhas são aplicadas identificando as pessoas que possuem ou não privação (etapa 5). Feito isso, contabiliza-se o número de privações de cada indivíduo (etapa 6).

O estágio posterior (etapa 7) implica na definição do segundo corte, denominado k. Adotando os critérios sugeridos por Alkire e Foster e por uma questão de simplificação, todas as dimensões assumem pesos iguais, obtido pela razão 10/3. A partir desse momento identifica-se a quantidade de indicadores que o indivíduo sofre privação, em seguida define-se critério para caracterização da 
pobreza multidimensional com base no número de variáveis onde haja privação. Após essas definições aplica-se o corte $\mathrm{k}$ com $\mathrm{o}$ intuito de obter $\mathrm{o}$ conjunto de pessoas pobres e não pobres (etapa 8). Considerando que a pesquisa busca analisar a pobreza e as dimensões onde há carência excluem-se da matriz as informações sobre os "não pobres" substituindo seus respectivos dados por zero.

Figura 1 - Passo a passo para aplicação do Índice de Pobreza Multidimensional de acordo com a metodologia proposta por Alkire e Foster.

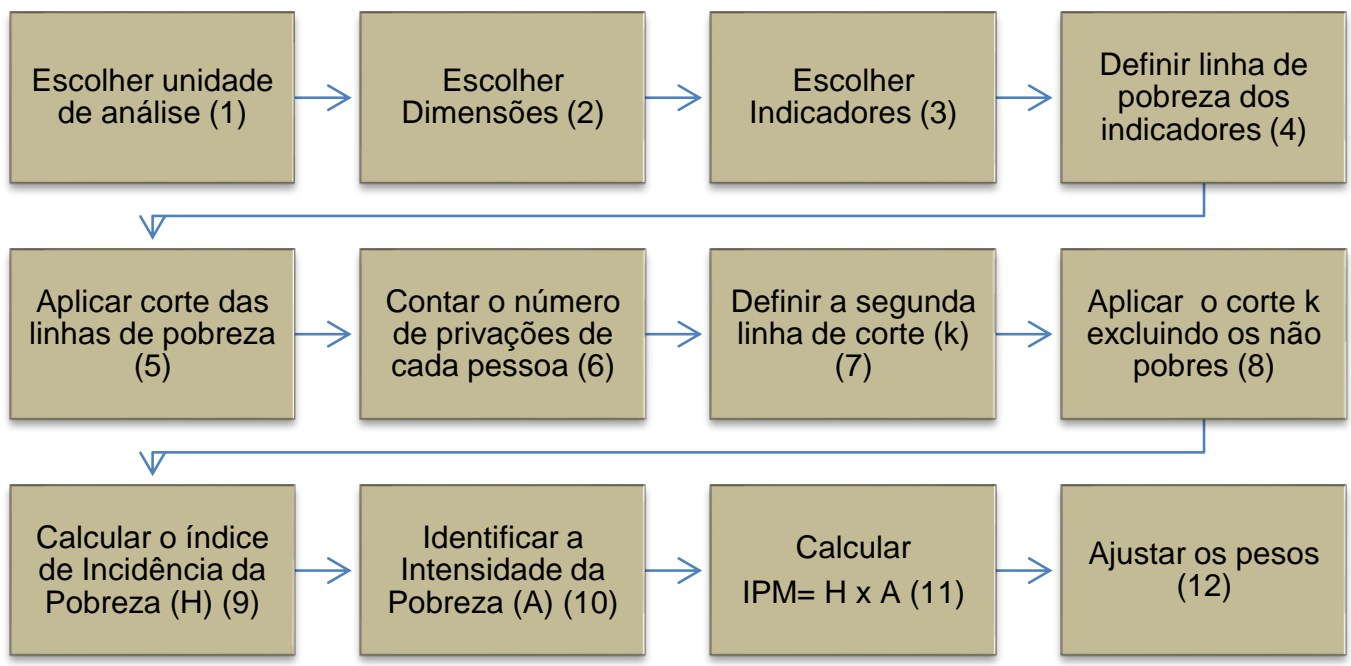

Fonte - Elaboração própria com base nos dados fornecidos pela OPHI (s/d b).

Os proponentes da metodologia admitem e fomentam a discussão quanto ao uso de pesos distintos para os indicadores, entretanto, em seus estudos o IPM é aplicado com base em dimensões igualmente ponderadas assim como seus indicadores primários. A opção por manter pesos iguais para as três dimensões é justificada por Alkire e Santos (2010) a partir de discussões e testes de robustez do Índice de Desenvolvimento Humano, além da opinião de especialistas e análises participativas.

O próximo passo (etapa 9) visa identificar o Índice de Incidência $H$, que corresponde a proporção da população considerada multidimensionalmente pobre em relação ao total, para isso, divide-se o número de pessoas pobres (q) pelo número total da amostra (n), definida por Alkire e Santos (2010) através da equação 1:

$$
\mathrm{H}=\frac{\mathrm{q}}{\mathrm{n}} \quad(0 \leq \mathrm{H} \leq 1)
$$

Dessa forma são estabelecidos dois tipos de corte, incialmente são determinadas as condições de privação de cada indicador, e em seguida definem-se, a partir da soma dos pesos de cada privação, os indivíduos classificados como pobre.

Para Alkire e Santos (2010) o corte k pode assumir qualquer valor entre 0 e 10, nesse trabalho optouse por manter a mesma linha utilizada pelas autoras, ou seja, identifica-se como multidimensionalmente pobres os domicílios/indivíduos que sejam privados de uma combinação de indicadores, cuja soma ponderada seja igual ou superior a $30 \%$ das dimensões, o que significa um $\mathrm{k}$ $\geq 0,30$. Esse ponto de corte de distinção equivale a um terço dos indicadores ponderados e, consequentemente ao peso de uma dimensão, por esse motivo Alkire e Foster (2007) adotam esse parâmetro considerando que deve ser classificado como pobre quem seja privado no equivalente a uma dimensão.

A metodologia procede, com o cálculo da Intensidade da Pobreza $(A)$, que evidencia o número médio de privações que um indivíduo pobre sofre (etapa 10). Para tal, soma-se a proporção total de cada pessoa que sofre privação $\left(\sum_{\mathrm{i}=1}^{n} \mathrm{Ci}(\mathrm{k})\right)$, dividindo pela multiplicação do número total de pessoas pobres (q) pelo número de indicadores (d), representado por Alkire e Santos (2010) conforme equação 2: 


$$
\mathrm{A}=\frac{\sum_{\mathrm{i}=1}^{\mathrm{n}} \mathrm{Ci}(\mathrm{k})}{\mathrm{qd}}
$$

Em seguida calcula-se o IPM (etapa 11) que pode ser definido através do $M_{0}$ obtido por uma seleção especial de dimensões, indicadores e pesos, resultando da soma ponderada das privações dos indivíduos pobres dividido pelo total da amostra vezes o número de indicadores (ALKIRE; SANTOS, 2010). Encontrado convencionalmente por meio da equação 3:

$$
\mathrm{M}_{0}=\sum_{\mathrm{i}=1}^{\mathrm{n}} \sum_{\mathrm{j}=1}^{\mathrm{d}} \mathrm{g}_{\mathrm{ij}}^{0} / \mathrm{nd}
$$

Esse índice corresponde ao valor médio dos escores de privação C na amostra e pode ser representado através do produto do Índice de Incidência $(\mathrm{H})$ pelo Índice de Intensidade da Pobreza (A), conforme a equação 4, em que:

$$
\mathrm{IPM}=\mathrm{H} \times \mathrm{A}
$$

Quanto maior o resultado do IPM - situado no intervalo entre 0 e 1, maior nível de pobreza multidimensional na área de estudo. Finalmente, ajustam-se os pesos das dimensões e indicadores igualmente ponderados (etapa 12), obtendo o valor do índice. Os resultados dessas medidas permitem além de observar a dimensão da pobreza em determinada localidade, identificar onde está aglomerada, onde se situa e as principais características que colaboram para que o indivíduo ou domicílio seja considerado pobre. Informações fundamentais no direcionamento de ações governamentais que visem reduzir e erradicar esse fenômeno.

\section{FONTE DE DADOS}

A fonte de dados para o cálculo do IPM consiste no questionário da amostra do último Censo Demográfico, referente ao ano de 2010, divulgado pelo IBGE. Essa base de dados possibilita verificar as informações por municípios e posteriormente agregá-las, em consonância com os objetivos da pesquisa. Todavia, trata-se de uma amostra, o que exige cautela na interpretação e generalizações.

O foco da análise se dá na comparação das áreas rurais e urbanas, sendo necessário separar as informações referentes aos domicílios urbanos e rurais. Salienta-se que algumas das variáveis sugeridas no índice de pobreza multidimensional não são abordadas no questionário do censo amostral, o que exige a utilização de proxies.

\section{SELEÇÃo dAS VARIÁVEIS}

Optou-se por manter as três dimensões sugeridas pela metodologia de cálculo do IPM, entretanto, as variáveis que compõem os indicadores foram cerceadas pela indisponibilidade de algumas informações na base de dados escolhida, haja vista que o censo demográfico não abrange elementos relacionados aos indicadores "piso" e "combustível para cozinhar" (componentes da dimensão padrão de vida), e de "nutrição", apesar de sua extrema importância para análise da multidimensionalidade da pobreza (componente da dimensão saúde).

Diante da ausência de determinadas informações na base de dados e da flexibilidade para a construção do IPM, a alternativa se deu através da redefinição de algumas variáveis. Quanto ao indicador piso utilizou-se a proxy de material predominante nas paredes do domicílio; na dimensão saúde, utilizou-se uma proxy de capacidade de se alimentar com base na linha de indigência elaborada por Rocha (IETS, s/d) para suprir a ausência de informações relacionadas a capacidade nutricional; finalmente, para compor a dimensão padrão de vida, substituiu-se a variável combustível para cozinhar pela variável destino do lixo, devido a disponibilidade de dados e por entender que a coleta indevida ou sua ausência acarreta futuros problemas à saúde pública e preservação ambiental.

Com relação à variável água, o censo demográfico não faz referência a potabilidade, apenas à forma de abastecimento de água e se existe canalização, portanto, essas foram as variáveis consideradas. Admite-se a restrição dessas escolhas, entretanto foram as alternativas mais viáveis para não comprometer o resultado do índice.

O Quadro 1 indica as variáveis que serão utilizadas para o cálculo do índice e as condições que caracterizem suas respectivas privações. Outrossim, foram definidos os pesos referentes, como cada 
Camilla Rusciolelli Barbosa

dimensão equivale a $1 / 3$ e cada variável que o compõe é igualmente ponderada, o peso final foi obtido através da divisão do valor da dimensão pela quantidade de indicadores que a compõe.

Quadro 1 - Seleção das variáveis utilizadas no Índice de Pobreza Multidimensional.

\begin{tabular}{|c|c|c|c|c|}
\hline Dimensão & Indicador & Condição de Privação & $\begin{array}{l}\text { Unidade de } \\
\text { análise }\end{array}$ & Peso \\
\hline \multirow{2}{*}{ 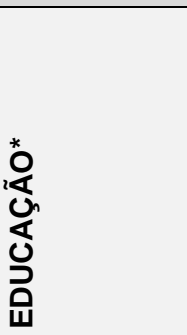 } & $\begin{array}{l}\text { Anos de escolaridade } \\
\text { (Nível de instrução) }\end{array}$ & $\begin{array}{l}\text { Não conclusão do ensino fundamental } \\
\text { ( } 8^{\text {a }} \text { série ou } 9^{\circ} \text { ano) para os indivíduos } \\
\text { que possuem } 18 \text { anos ou mais (idade } \\
\text { laboral). }\end{array}$ & Indivíduo & 1,67 \\
\hline & Frequência escolar & $\begin{array}{l}\text { Existência de criança com idade } \\
\text { superior a } 6 \text { anos que não frequente } \\
\text { escola. }\end{array}$ & Domicílio & 1,67 \\
\hline \multirow[b]{2}{*}{ 茪 } & Mortalidade infantil & $\begin{array}{l}\text { Ocorrência de óbito de crianças com até } \\
1 \text { ano de idade. }\end{array}$ & Domicílio & 1,67 \\
\hline & $\begin{array}{l}\text { Capacidade monetária de } \\
\text { se alimentar }\end{array}$ & $\begin{array}{l}\text { Para os domicílios urbanos considerou- } \\
\text { se renda per capita inferior a } R \$ 57,03 \text {, } \\
\text { para os rurais } R \$ 49,54 \text {. }\end{array}$ & Indivíduo & 1,67 \\
\hline \multirow{6}{*}{ 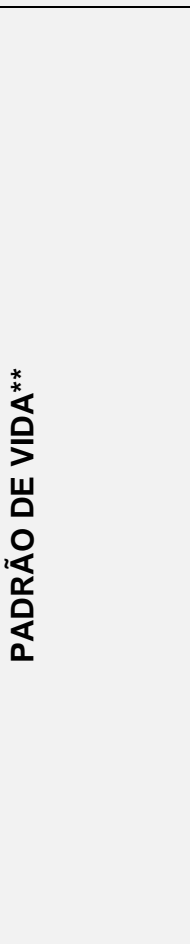 } & Acesso à Eletricidade & $\begin{array}{l}\text { Ausência de acesso à energia elétrica } \\
\text { no domicílio. }\end{array}$ & Domicílio & 0,56 \\
\hline & Abastecimento de Água & $\begin{array}{l}\text { Ausência de água canalizada no } \\
\text { domicílio ou na propriedade oriunda de } \\
\text { rede geral (no urbano) e, além dos } \\
\text { anteriores, de rede geral, água da chuva } \\
\text { armazenada em cisterna, poço ou } \\
\text { nascente na propriedade, poço ou } \\
\text { nascente na aldeia (no rural). }\end{array}$ & Domicílio & 0,56 \\
\hline & Saneamento & $\begin{array}{l}\text { Possuir banheiro e não possuir } \\
\text { esgotamento sanitário adequado, ou } \\
\text { ausência de banheiro de uso exclusivo. }\end{array}$ & Domicílio & 0,56 \\
\hline & $\begin{array}{l}\text { Material predominante nas } \\
\text { paredes }\end{array}$ & $\begin{array}{l}\text { Ausência de parede de alvenaria com } \\
\text { ou sem revestimento, ou de madeira } \\
\text { apropriada para construção. }\end{array}$ & Domicílio & 0,56 \\
\hline & Coleta do lixo & $\begin{array}{l}\text { Lixo não coletado diretamente por } \\
\text { serviço de limpeza ou em caçamba de } \\
\text { serviço de limpeza. }\end{array}$ & Domicílio & 0,56 \\
\hline & Ativos & $\begin{array}{l}\text { Não possuir pelo menos dois dos ativos } \\
\text { (rádio, televisão, geladeira, celular, } \\
\text { telefone fixo, motocicleta, automóvel). }\end{array}$ & Domicílio & 0,56 \\
\hline
\end{tabular}

Fonte - Elaboração própria a partir de dados do OPHI e IBGE.

*Cada indicador é igualmente ponderado em 10/6; ** Cada indicador é igualmente ponderado em 10/18.

Ao definirmos as variáveis e as condições de privação devemos atentar para as diferenças entre as situações predominantes no âmbito urbano e rural. No Brasil, o acesso ao saneamento, coleta de lixo e água canalizada, por exemplo, é mais precário à medida que se distancia dos centros urbanos.

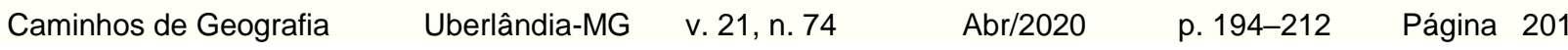


Entretanto, apesar de reconhecer esse cenário, é inegável a necessidade e o direito de que todos vivam em condições adequadas.

De acordo com o Relatório Nacional de Acompanhamento dos ODMs de 2014, são considerados assentamentos precários os domicílios que não possuem acesso à água potável e ao esgotamento sanitário, casas construídas com materiais não duráveis ou que possuam adensamento populacional de 3 ou mais pessoas por dormitório (BRASIL, 2014). Com base nessas características, quanto ao indicador água, serão considerados em condição de privação os domicílios que não tiverem água canalizada na residência ou na propriedade oriunda de rede geral, para os domicílios urbanos, ou de rede geral, água da chuva armazenada em cisterna, poço ou nascente na propriedade, poço ou nascente na aldeia, para aqueles localizados em áreas rurais.

Quanto à variável saneamento, serão considerados em condição de privação os domicílios que possuírem banheiro e não possuírem esgotamento sanitário adequado, ou ausência de banheiro de uso exclusivo. Definiram-se por esgotamento sanitário adequado os domicílios localizados na área urbana que possuam rede geral de esgoto ou fossa séptica, e rede geral, fossa séptica ou rudimentar para os rurais.

Com relação à coleta do lixo a sua inexistência ou realização de forma inadequada também caracteriza a presença de privação, bem como a ausência de parede de alvenaria com ou sem revestimento ou construída com madeira inapropriada. Além disso, a falta de energia elétrica nos domicílios e a carência dos bens de consumo relacionados no indicador "ativos" foram consideradas como predicado de privação.

No que se refere à dimensão educação, tem-se sua composição através dos indicadores anos de escolaridade e frequência escolar. Um dos Objetivos do Milênio consiste na tentativa de que todos tenham acesso à educação de qualidade, além disso, esse é um dos direitos assegurados pela Constituição Federal (BRASIL, 1988) e pelo Estatuto da Criança e do Adolescente. Desse modo, será considerado em condição de privação o domicílio em que os indivíduos com idade superior a 18 anos que não tenham concluído pelo menos o ensino fundamental, uma média de cinco anos de estudo, haja vista que de acordo com o caput do artigo $5^{\circ}$ da Lei no 9.394, alterada pela Lei no 12.796 , "o acesso à educação básica obrigatória é direito público subjetivo" (BRASIL, 1996). Além disso, a metodologia proposta por Alkire e Foster indica como privado o domicílio em que nenhum membro da família tenha estudado por pelos menos cinco anos. Considerou-se nessa linha de corte os maiores de 18 anos por se tratar da idade mínima laboral no Brasil. Para tal, serão utilizadas as repostas do censo que indiquem o curso mais elevado que o indivíduo já tenha cursado e a idade.

Quanto à variável "frequência escolar", será julgado em condição de privação o domicílio em que haja criança com idade superior a seis anos e que ainda não tenha acesso à primeira etapa da educação básica. A faixa etária foi assim definida com base no texto da Lei Federal 11.114 de 16 de maio de 2005 que altera o texto da Lei de no 9.394 de Diretrizes e Bases da Educação Nacional (LDB), e reduz para seis anos a idade na qual os pais ou responsáveis devem efetuar a matrícula dos menores, tornando obrigatório o acesso ao ensino fundamental nesse período (BRASIL, 1996).

No tocante a dimensão saúde, a variável mortalidade infantil teve sua condição de privação atribuída aos domicílios em que houve falecimentos de crianças com idade inferior a um ano. Para o Estatuto da Criança e do Adolescente, considera-se criança pessoas com até 12 anos de idade incompletos, já as estimativas de mortalidade infantil do governo brasileiro adotam os óbitos dos menores de um ano de idade (IBGE, 2013), optando-se, portanto, por essa última definição.

O banco de dados utilizado na pesquisa não faz menção a elementos relativos à variável capacidade nutricional, dessa maneira, diante da sua extrema importância para caracterização multidimensional da pobreza, decidiu-se utilizar uma proxy denominada de capacidade monetária para se alimentar, estimada a partir da linha de indigência definida por Sônia Rocha com base na POF, disponibilizada através do Instituto de Estudos do Trabalho e Sociedade - IETS. Foram considerados como privados nessa variável os indivíduos residentes na área urbana com rendimento inferior a $R \$ 57,04$ por mês, e $\mathrm{R} \$ 49,54$ na zona rural (IETS, s/d).

Entende-se que as medidas multidimensionais de pobreza visam enxergar as privações sob outros aspectos que não apenas o da renda, entretanto, compreendendo a importância de mensurar a capacidade que os indivíduos possuem ou não para obter a alimentação mínima necessária para 
sobrevivência, considerou-se sensato incluir essa variável a análise, objetivando manter os dez indicadores tal qual a metodologia inicial, sem suprimir informações de tamanha relevância.

\section{RESULTADOS E DISCUSSÃO}

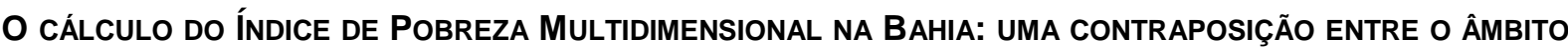 RURAL E URBANO}

Esta seção aborda a análise do cálculo do Índice de Pobreza Multidimensional na Bahia a partir das três dimensões trabalhadas (educação, saúde e padrão de vida), considerando os resultados para as zonas rural e urbana.

E, de forma preliminar, são apresentadas informações gerais do estado da Bahia e do Brasil, para fins comparativos, acerca da população, densidade demográfica, educação (através do índice de Desenvolvimento para a Educação), desenvolvimento (através do índice de Desenvolvimento Humano) e taxa de urbanização, que considera a razão entre a população urbana e sua totalidade (Tabela 1).

Tabela 1 - Dados baianos e nacionais sobre população, densidade demográfica, educação, desenvolvimento e urbanização.

\begin{tabular}{l|l|l|l|l|l|l}
\hline & População* & $\begin{array}{l}\text { Densidade } \\
\text { demográfica } \\
\left(\text { hab./ } \text { km}^{2}\right)^{\star}\end{array}$ & $\begin{array}{l}\text { PIB per } \\
\text { capita** }\end{array}$ & $\begin{array}{l}\text { IDEB } \\
\text { iniciais / anos } \\
\text { finais }\end{array}$ & IDH $^{\star \star \star \star}$ & $\begin{array}{l}\text { Taxa de } \\
\text { urbanização* }\end{array}$ \\
\hline Bahia & 14.016 .906 & 24,82 & $11.007,00$ & $4,7 / 3,4$ & 0,66 & $72 \%$ \\
\hline Brasil & 190.755 .799 & 22,41 & $31.833,50$ & $5,5 / 4,4$ & 0,69 & $84 \%$ \\
\hline
\end{tabular}

Nota: *2010; ** Produto Interno Bruto per capita para o ano de 2018; ${ }^{* \star *}$ Índice de Desenvolvimento para a Educação Básica para o ano de 2017; *** Índice de Desenvolvimento Humano.

Os dados mais recentes sobre o estado mostram que o mesmo, em 2010 , abarcava $7,34 \%$ da população brasileira. Para as demais variáveis em estudo, o estado apresentou-se muito aquém dos resultados nacionais, no qual o PIB per capita era de quase 1/3 do PIB per capita nacional. O IDEB, $\mathrm{IDH}$ e a taxa de urbanização também foram inferiores à média brasileira, exibindo as heterogeneidades regionais presentes no território.

\section{ANÁLISE DOS INDICADORES}

O quadro 2 apresenta um comparativo das privações vivenciadas pelos indivíduos que residem na zona rural e na zona urbana, delimitados pela área de localização, tomando por base a legislação vigente durante a realização do censo demográfico de 2010. São considerados pertencentes à área urbana as cidades (sedes municipais), as vilas (sedes distritais) ou as áreas urbanas isoladas. A zona rural, por sua vez, corresponde à área não pertencente a esse limite.

\section{EDUCAÇÃo}

A primeira variável diz respeito aos indivíduos com idade superior a 18 anos que não completaram o ensino fundamental. Os resultados retratam a precariedade da educação na Bahia, sobretudo no âmbito rural, cuja população privada corresponde a $66,19 \%$ do total. Apesar das três unidades de análise apresentarem altos índices de privação é evidente a proeminência no meio rural (Quadro 2). 
Pobreza sob a ótica multidimensional no Estado da Bahia, Brasil: uma análise do rural e urbano
Camilla Rusciolelli Barbosa

Monick Midlej do Espírito Santo Andréa da Silva Gomes Mônica de Moura Pires Fernanda Calasans Costa Lacerda Pessoti

Quadro 2 - Percentual (\%) de privação na Bahia, segundo os indicadores utilizados no cálculo do IPM, 2010.

\begin{tabular}{|c|c|c|c|c|}
\hline & Indicadores & Rural & Urbano & Geral \\
\hline \multirow{2}{*}{ 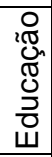 } & $\begin{array}{l}\text { Percentual de indivíduos maiores de } 18 \text { anos que não completaram o ensino } \\
\text { fundamental ( } 8^{\underline{a}} \text { série ou } 9^{\circ} \text { ano) }\end{array}$ & 66,19 & 30,63 & 38,83 \\
\hline & Percentual de crianças maiores de 6 anos fora da escola & 3,3 & 3,05 & 3,13 \\
\hline \multirow{2}{*}{ 竞 } & Percentual de óbitos de menores de um ano de idade & 0,11 & 0,09 & 0,09 \\
\hline & Percentual de privação de acordo com a capacidade monetária para se alimentar & 4,67 & 3,68 & 3,96 \\
\hline \multirow{6}{*}{$\begin{array}{l}\frac{\pi}{2} \\
\frac{0}{2} \\
\frac{0}{0} \\
0 \\
0 \\
\frac{\pi}{0} \\
\frac{\pi}{0} \\
0\end{array}$} & Percentual de privação de acordo com o acesso à eletricidade nos domicílios & 11,23 & 0,57 & 3,54 \\
\hline & $\begin{array}{l}\text { Percentual de privação de acordo com a forma de abastecimento de água nos } \\
\text { domicílios }\end{array}$ & 37,63 & 5,62 & 14,53 \\
\hline & $\begin{array}{l}\text { Percentual de privação de acordo com as condições de saneamento nos } \\
\text { domicílios }\end{array}$ & 42,4 & 35,83 & 36,66 \\
\hline & $\begin{array}{l}\text { Percentual de privação de acordo com o tipo de material predominante da parede } \\
\text { nos domicílios }\end{array}$ & 11,03 & 2,09 & 4,59 \\
\hline & Percentual de privação de acordo com a forma de coleta de lixo nos domicílios & 80,31 & 5 & 26,03 \\
\hline & $\begin{array}{l}\text { Percentual de privação de acordo com a posse de bens de consumo na Bahia em } \\
2010\end{array}$ & 14,3 & 2,9 & 6,08 \\
\hline
\end{tabular}

Fonte - Elaboração própria com base nos microdados do Censo Demográfico - IBGE (2010).

Os valores de incidência de privação para essa variável ratificam os números retratados através do IDH que retratou os baixos índices de educação do estado.

Frente à precariedade do ensino na Bahia, iniciativas como o FUNDEF e o FUNDEB foram implementadas e a resposta a essas ações pode ser observada na segunda variável analisada, a qual diz respeito ao acesso de crianças em idade escolar - seis anos, segundo a legislação vigente em 2010 - que frequentavam a escola. Os resultados foram menores e mais uniformes em relação a variável anterior, situando em torno de $3 \%$ de privação (Quadro 3). Soma-se a isso, entre outros fatores, a exigência da frequência escolar estabelecida pelos programas de transferência de renda do Governo Federal, cujo recebimento do benefício fica atrelado à matrícula e assiduidade das crianças na escola.

Contudo, apesar dos esforços recentes destinados a ampliação da cobertura escolar, a educação pública de qualidade ainda requer alguns avanços para atingir o nível satisfatório e deixar de ser um dos principais problemas estruturais do estado.

\section{SAÚDE}

Diante das dificuldades ainda enfrentadas por uma significativa parcela da sociedade, salienta-se que os indicadores utilizados nesse IPM, por si só, não são capazes de retratar a real situação do setor de saúde no estado da Bahia, que abrange quantidade de profissionais contratados, número de leitos hospitalares e medidas de saúde preventiva, por exemplo.

A dimensão saúde foi a que apresentou as menores incidências de privação, sendo o indicador mortalidade infantil inferior a todos os outros (Quadro 3). O corte de privação para essa variável foi definido pela existência de óbito de crianças antes de completarem um ano de idade, adotando como critério a tábua de mortalidade do IBGE (2013).

É importante salientar a tendência de redução da mortalidade infantil em todas as regiões do país apresentada no levantamento realizado pela REDE (2002).

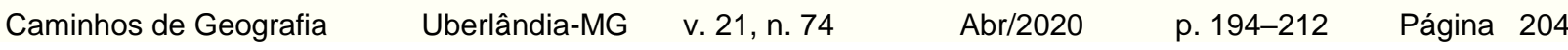


O segundo indicador a compor a dimensão saúde visa representar o percentual de indivíduos, sejam eles adultos ou crianças, que não possui condições de nutrição adequadas. Consoante ao que afirmam Alkire e Santos (2010), o consumo de alimentos consiste em um indicador universalmente relevante, entretanto os dados referentes a esse aspecto disponíveis em pesquisas costumam ser limitados e na maioria das vezes permitem apenas uma distribuição proporcional para cada membro dentro do agregado familiar com base no consumo geral, suposição essa que nem sempre é exata.

Como exposto na metodologia, foi necessária a utilização de uma proxy de capacidade monetária de se alimentar segundo as linhas de indigência elaborada por Sônia Rocha e disponibilizada pelo IETS (s/d). A escolha por essa linha justifica-se pelo ajuste realizado a cada ano pela variação dos INPC regionais em nível de grupos de produtos, além de estabelecer diferentes valores para os domicílios urbanos e rurais (IETS, s/d). Em 2010 a linha de indigência per capita definida para a Bahia foi de $R$ \$ 57,03 no contexto urbano e $R \$ 49,54$ no rural. Salienta-se que no meio rural o acesso a alimentos não se restringe aos rendimentos monetários, tendo em vista a possibilidade da produção para subsistência. Essa característica reflete-se nos diferentes valores adotados para as linhas de indigência.

Admitem-se as limitações em utilizar uma variável pautada nos rendimentos para identificar as privações nutricionais de um indivíduo, como ressaltou Schwartzman ao IETS (2011): "Associar renda com nutrição é tratar de questões muito distintas. Existe um problema que é o da renda mínima para consumo de alimentos, e existe um outro problema, do campo da nutrição." Ademais as abordagens multidimensionais buscam entender a pobreza sob outras perspectivas.

Quando comparada a outras dimensões, o percentual de privação de acordo com a capacidade monetária para se alimentar obteve valores relativamente baixos (Quadro 3). Essa condição está relacionada à valorização do salário mínimo e ao aumento da destinação de recursos públicos à transferência de renda direta.

\section{PADRÃo de VIDA}

Os indicadores pertencentes à dimensão padrão de vida estão relacionados às condições de habitação e elencam características dos domicílios. Observou-se especialmente nesses quesitos elevada incidência de privações nos domicílios localizados na zona rural, em geral, bastante superior aos valores dos domicílios urbanos.

No indicador que relaciona o percentual de privação segundo o acesso à eletricidade, praticamente não há restrições entre as residências urbanas (0,57\%), já no âmbito rural, $11,23 \%$ apresentaram privação (Quadro 3).

Quanto ao indicador forma de abastecimento de água nos domicílios, utilizou-se uma proxy para substituir a variável acesso a água potável, como descrito na metodologia, e observou-se que os domicílios rurais apresentaram níveis muito superiores de privação, em comparação ao urbano.

Quanto às condições de saneamento e esgotamento sanitário, os dados mostraram-se relativamente altos para a Bahia devido à utilização de formas de esgotamento sanitário inadequadas, não sendo observadas diferenças significativas entre rural e urbano (Quadro 3). Esse é um problema que precisa ser tratado pontualmente, pois trazem prejuízos à saúde das pessoas e à conservação do meio ambiente. 
Quanto ao tipo de material predominante nas paredes, a maior incidência de privação foi para o meio rural $(11,03 \%)$. Esta variável é uma proxy para a variável utilizada no IPM sobre piso dos domicílios. Considerou-se não privação a predominância de parede de alvenaria com ou sem revestimento, ou construída com madeira apropriada.

$\mathrm{Na}$ variável coleta de lixo, o percentual de pessoas na Bahia sem acesso a esse tipo de serviço público no domicílio preocupa. Apenas $19,69 \%$ da população meio rural não enfrenta tal privação, sendo a situação mais agravante em termos de amplitude da incidência (Quadro 3). Esta variável foi incluída em substituição a variável "Combustível para cozinhar", e reflete a prática consolidada de ações insustentáveis do ponto de vista ambiental.

Sabe-se da dificuldade em garantir a cobertura da coleta aos locais mais distantes dos centros urbanos, entretanto, essa justificativa não elimina os efeitos dessa privação. Diante da ausência da coleta de lixo adequada, seja ela privada ou particular, os resíduos sólidos produzidos na zona rural são enterrados, queimados ou jogados em terrenos baldios.

A precariedade na prestação desse tipo de serviço, agravada no meio rural, torna suscetível o crescimento dos problemas ambientais, como por exemplo, a contaminação da água e do solo, fator que pode comprometer a saúde da população como um todo e a sustentabilidade de gerações futuras. Os riscos causados ao equilíbrio ambiental somam ainda a peculiaridade do lixo rural ser composto por dejetos relacionados à produção agrícola, que inclui defensivos, adubos, produtos químicos, restos vegetais, além dos resíduos resultantes do cotidiano dos indivíduos.

O último indicador estipula a propriedade de bens de consumo duráveis, denominado de ativos. Nesse sentido, adotou-se como ausência de privação possuir pelo menos dois dos seguintes ativos: rádio, televisão, geladeira, aparelho celular, telefone, motocicleta, ou se possuir automóvel. Na área rural essa variável também apresentou resultado relativamente elevado (Quadro 3), confirmando a hipótese de que os indivíduos desse meio sofrem mais privações que os da zona urbana também nesse quesito.

Esse comportamento tem sua principal causa relacionada ao percentual de privação segundo o acesso à eletricidade, já que no âmbito rural $11,23 \%$ dos indivíduos são privados nessa variável e a maioria dos ativos analisados depende da eletricidade para o funcionamento. Em efeito, os indivíduos têm seu acesso a determinados bens de consumo cerceados, entre outros fatores, pela ausência de energia elétrica no domicílio.

\section{AplicaÇão e anÁlise do Indicador de Pobreza Multidimensional para a BaHIa}

Os resultados obtidos são compostos pelas medidas de Incidência da Pobreza $(H)$ que indica a proporção dos multidimensionalmente pobres presentes na amostra, e Intensidade da Pobreza (A) que visa refletir a proporção de privações média sofridas. Após o cálculo da matriz de privação contendo apenas os pobres do ponto de vista multidimensional, calculou-se o valor de A, cuja intensidade da pobreza na Bahia obteve valor de 0,370 , enquanto para incidência $(H) \circ$ valor foi igual a 0,255 . O produto dessas duas medidas resultou no valor do IPM igual a 0,0941 para o estado de forma geral. $\mathrm{O}$ mesmo procedimento foi realizado para encontrar os valores para o meio urbano e rural (Figura 2). 
Camilla Rusciolelli Barbosa

Figura 2 - Incidência, intensidade e IPM para a Bahia (Geral, urbano e rural), em 2010.

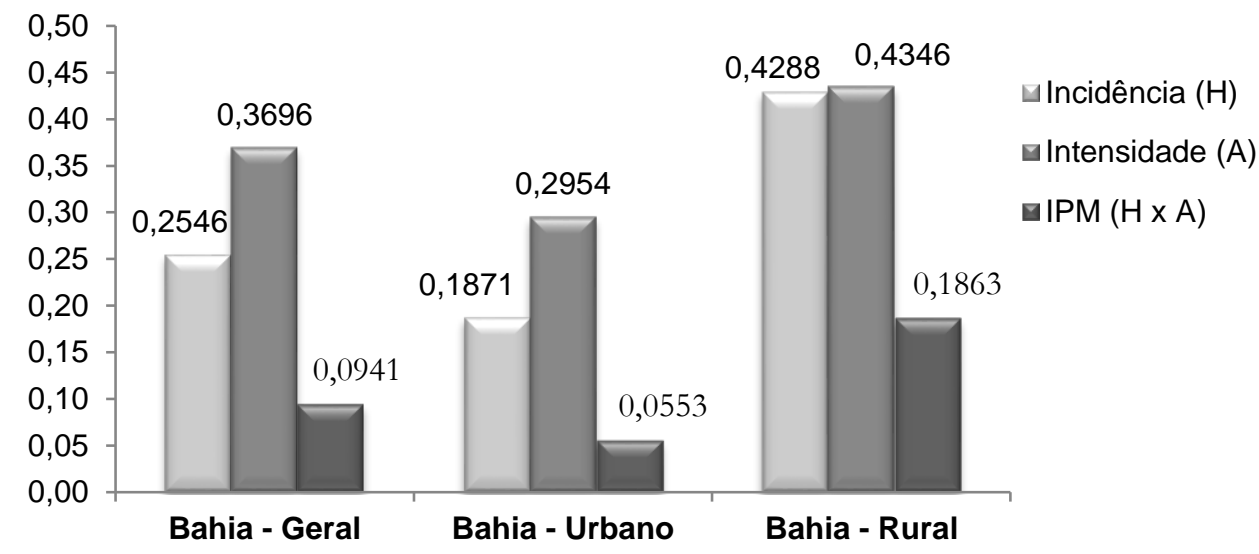

Fonte - Elaboração própria com base nos microdados do Censo Demográfico - IBGE (2010).

Enquanto o $\mathrm{H}$ indica a proporção de indivíduos considerados pobres, o A nos permite captar as desigualdades dentro da própria pobreza. Na área urbana, o número proporcional de pessoas consideradas pobres, bem como a intensidade da pobreza, foi bastante inferior aos valores encontrados quando analisados o contexto geral e rural. Os dados estimados indicam que $18,71 \%$ da população urbana foram considerados pobres, ao passo que dentre a população rural $42,88 \%$ estavam nessa condição. A intensidade da pobreza foi a medida que apresentou os maiores valores nos três contextos e, como esperado, as privações contidas no âmbito rural superaram o urbano.

As discrepâncias seguem na quantidade de municípios que possuem maior ou menor proporção de pobres em cada subconjunto. Quando se observa apenas o ambiente urbano, a maioria dos municípios (81\%) possui o índice $\mathrm{H}$ inferior a $30 \%$. Já no ambiente rural, $82 \%$ dos municípios têm o valor de $\mathrm{H}$ situado nas faixas superiores a $30 \%$, ou seja, com mais de $30 \%$ da população sofrendo múltiplas privações (Figura 3).

Figura 3 - Distribuição da incidência da pobreza $(H)$ entre os municípios baianos por situação do domicílio urbano (a)/rural (b).

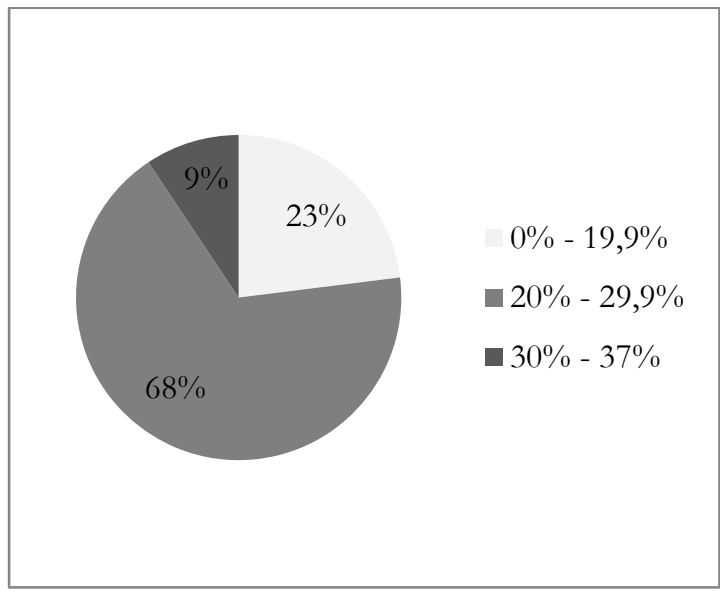

(a)

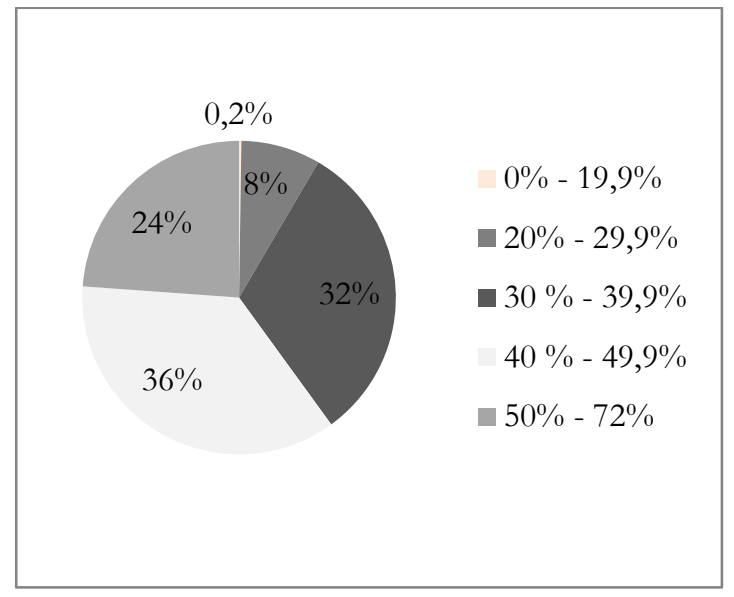

(b)

Fonte - Elaboração própria, com base nos microdados do Censo Demográfico - IBGE (2010). 
Embora a maior parte $(72,07 \%)$ do contingente populacional baiano resida em áreas urbanas, usando a abordagem do IPM, 52,98\% das pessoas consideradas multidimensinalmente pobres no estado residiam em áreas rurais em 2010. O padrão de concentração rural do índice é consistente e se reproduz entre os municípios.

As distinções encontradas segundo o critério de localização da unidade de análise (rural/urbano) podem ser mais bem compreendidas com o auxílio de medidas estatísticas descritivas indicadas no Quadro 3. Com exceção do valor mínimo, o IPM rural dos municípios baianos apresentou os maiores valores em todos os parâmetros analisados, ou seja, maior média, valor máximo, variância e desvio padrão, o que insinua maior ocorrência de pobreza multidimensional e maior variação dos valores da amostra em relação à média nesse subgrupo.

Quadro 3 - Estatística descritiva do Índice de Pobreza Multidimensional (IPM) para os municípios baianos, 2010.

\begin{tabular}{|c|c|c|c|}
\hline Medidas & Bahia -Geral & Bahia - Urbano & Bahia - Rural \\
\hline Média & 0,125 & 0,074 & 0,188 \\
\hline Valor Máximo & 0,272 & 0,150 & 0,361 \\
\hline Valor Mínimo & 0,031 & 0,031 & 0,016 \\
\hline Variância & 0,002 & 0,000 & 0,003 \\
\hline Desvio Padrão & 0,041 & 0,018 & 0,059 \\
\hline \% de pobres & $25,46 \%$ & $18,71 \%$ & $42,88 \%$ \\
\hline
\end{tabular}

Fonte - Elaboração própria com base nos microdados do Censo Demográfico - IBGE (2010).

O menor resultado para o IPM nos três contextos (geral, urbano e rural) corresponde ao município Madre de Deus, o qual apresenta um comportamento atípico, já que está localizado em uma llha na Região Metropolitana de Salvador, onde $97 \%$ da população residem na zona urbana, cujas fontes de renda concentram-se na atividade petrolífera - em maior parte, pesca artesanal e turismo. Quanto ao IDH, em 2010 foi igual a 0,708 , classificado como alto e ocupando a $7^{\text {a }}$ posição no ranking baiano (PNUD, IPEA, FJP, 2010; MADRE DE DEUS, 2015).

Em situação oposta, o município Pilão Arcado obteve o maior IPM rural e geral $(0,361$ e 0,272$)$, situado no norte do estado na microrregião de Juazeiro, é o terceiro pior desempenho do IDH na UF ocupando a $5510^{a}$ posição entre os 5.565 municípios brasileiros, motivado principalmente pelo baixo desempenho em educação (PNUD, IPEA, FJP, 2010). Na delimitação urbana as cidades que apresentaram os maiores IPM foram Caetanos e Campo Alegre de Lourdes.

Para facilitar a compreensão e permitir uma maior comparabilidade, especificamente nesse trabalho, a categorização para o IPM contemplará apenas o intervalo de valores encontrados para a mensuração da pobreza na Bahia, ou seja, entre 0,016 e 0,361, embora o IPM possa variar entre 0 e 1. Consideram-se 4 classes: i) IPM Baixo de 0 a 0,05; ii) IPM Médio-baixo de 0,05 a 0,1; iii) IPM Médio-alto de 0,1 a 0,2; e iv) IPM Alto de 0,2 a 0,4.

Partindo dessa classificação e de sua distribuição no território baiano é evidente o abismo social que existe entre os meios analisados. Ainda que exista uma similaridade no comportamento, onde os municípios mais pobres na zona rural são habitualmente os mais pobres na zona urbana, impressiona o fato de os valores para o índice mensurado apresentarem números muito mais elevados no contorno rural, no qual praticamente todos os municípios estão com o IPM classificado como Médioalto ou Alto (Figura 4). 
Figura 4 - Distribuição do IPM entre os municípios baianos por classificação em Urbano (a), Rural (b) ou Geral (c).

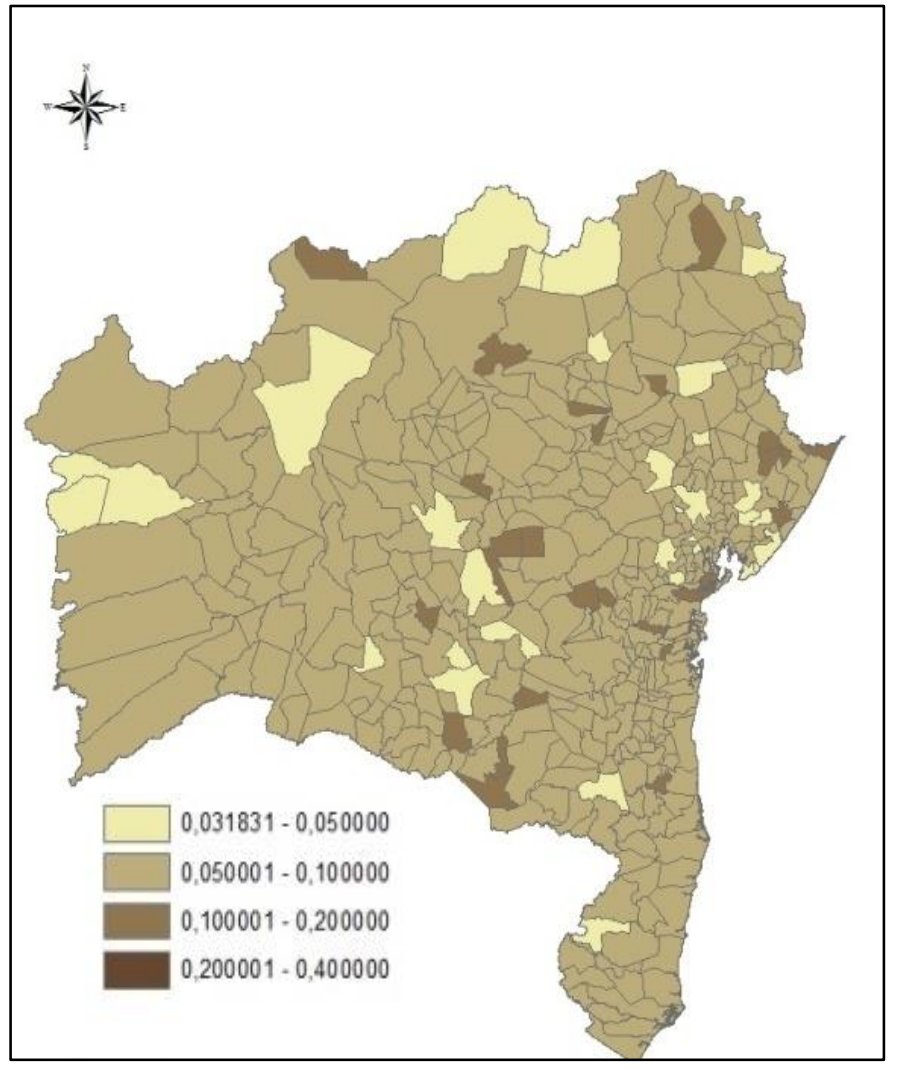

(a)

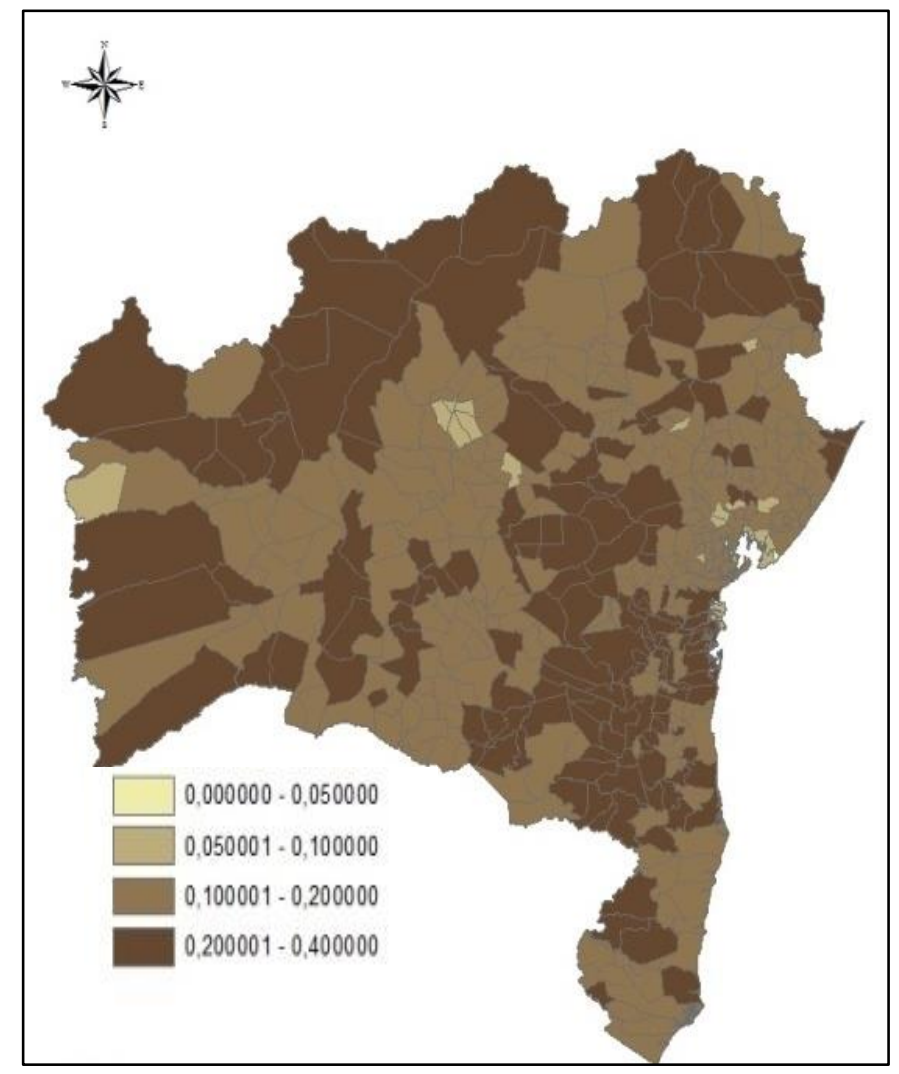

(b)

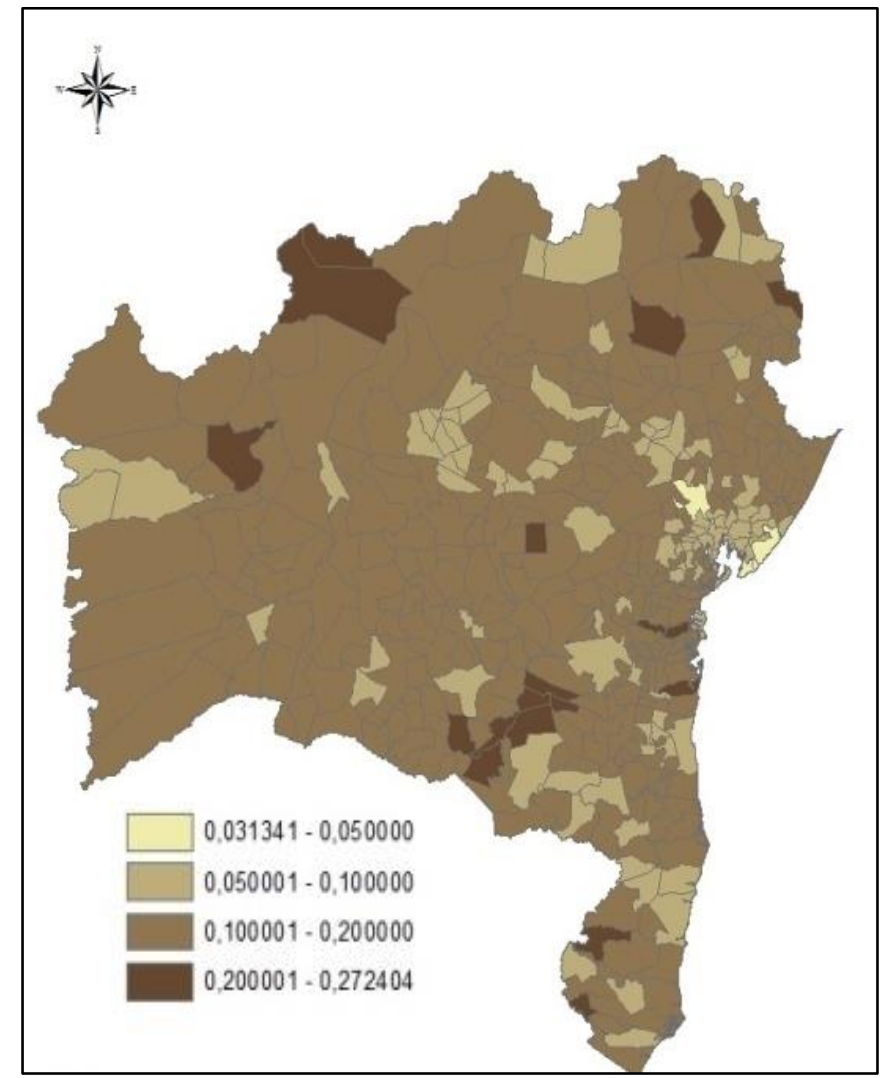

(c)

Fonte - Elaboração própria com base nos microdados do Censo Demográfico - IBGE (2010). 
O comportamento da distribuição da pobreza multidimensional, dentro dos parâmetros estabelecidos nessa pesquisa, pode ser compreendido de forma mais clara diante da definição de uma classificação e da observação da quantidade de municípios por faixa. Dentre os municípios baianos, quando observamos apenas a área urbana a maioria (359 municípios) está classificada com médio-baixo IPM (Figura 4 e tabela 2), já na área rural a classificação do índice concentra-se nas faixas médio-alta e alta (235 e 159 municípios respectivamente).

Tabela 2 - Frequência da pobreza multidimensional entre os municípios baianos na área rural, urbana e geral, segundo critério de classificação do IPM, 2010.

\begin{tabular}{c|c|c|c}
\hline \multirow{2}{*}{ Classificação do IPM } & \multicolumn{2}{|c}{ Número de municípios } \\
\cline { 2 - 4 } & Urbano & Rural & Geral \\
\hline Baixo (entre 0 e 0,050) & 36 & 1 & 6 \\
Médio-baixo (entre 0,051 e 0,100) & 359 & 20 & 292 \\
Médio-alto (entre 0,101 e 0,200) & 22 & 235 & 19 \\
Alto (acima de 0,200) & 0 & 159 & 100 \\
\hline
\end{tabular}

Fonte - Elaboração própria.

Cabe ressaltar que apenas um terço da população baiana reside fora dos limites urbanos, e que em determinados indicadores foram considerados diferentes cortes para as privações rurais e urbanas, entendendo as especificidades de cada meio. Ainda assim os níveis de pobreza são muito superiores na zona rural e ocasionam em uma situação de precariedade para todo o estado.

\section{CONSIDERAÇÕES FINAIS}

A contingência baiana, marcada pela severidade da pobreza multidimensional especificamente no meio rural, requer uma investigação complementar disposta a compreender os predicados que contribuem para tal. É fato que a riqueza precisa ser distribuída no território para uma quantidade mais abrangente de indivíduos. Entretanto, a renda não é o único fator a ser discutido, já que as análises se pautaram nas múltiplas privações que caracterizam a pobreza. As atenções devem estar voltadas a questões estruturais como saneamento, coleta de lixo, abastecimento de água e níveis de escolaridade, que foram os indicadores com maior incidência de indivíduos considerados privados. É indispensável ainda uma diversificação da cadeia produtiva baiana, gerando mais oportunidades a uma maior parcela da população.

As políticas públicas que buscam fornecer e valorizar diferentes alternativas econômicas são fundamentais em um estado territorialmente diversificado como a Bahia, onde as áreas prósperas convivem simultaneamente com regiões que enfrentam uma dura realidade refletida no contexto social e demográfico.

Examinar a pobreza com base em suas múltiplas implicações contribui para que as políticas sociais atuem de forma complementar, de modo a retirar o indivíduo da condição de pobreza. Especialmente no âmbito rural - para o qual os resultados desse estudo apontaram situação mais alarmante de incidência e privação da pobreza em relação ao urbano - é imperativo que as ações econômicas e sociais estejam integradas e sejam capazes de possibilitar ao indivíduo optar por estilos de vida que mais the agrade, sem ser necessariamente imposto a tal (capacidades). Dessa forma, o êxodo rural não deve ser visto como impositivo à sobrevivência e melhores condições de vida, mas como uma alternativa cuja escolha entre os dois meios não seja motivada pela precariedade presente na zona rural.

$\begin{array}{lllll}\text { Caminhos de Geografia } & \text { Uberlândia-MG } & \text { v. 21, n. } 74 & \text { Abr/2020 } & \text { p. 194-212 Página } 210\end{array}$




\section{AGRADECIMENTOS}

Os autores agradecem à Fundação de Amparo à Pesquisa do Estado da Bahia (FAPESB) e à Coordenação de Aperfeiçoamento de Pessoal de Nível Superior (CAPES) pelo apoio financeiro para a realização do artigo.

\section{REFERÊNCIAS}

ALKIRE, S., FOSTER, J. Recuento y medición multidimensional de la pobreza. OPHI Working Paper Series, $n^{\circ} 7$, p. $1-45,2007$.

ALKIRE, S., SANTOS, M. A. Acute Multidimensional Poverty: A New Index for Developing Countries. OPHI Working Paper Series, n 38, p. 1 - 139, 2010. https://doi.org/10.2139/ssrn.1815243

BARROS, R. P. de; CARVALHO, M. de; FRANCO, S. Pobreza Multidimensional no Brasil. Texto para discussão n 1227. IPEA: Rio de Janeiro, 2006.

BRASIL. Constituição da República Federativa do Brasil: promulgada em 05 de outubro de 1988 [atualizada], 1988.

. Diretrizes e Bases da Educação Nacional. Lei ํo 9.394 de 20 de dezembro de 1996 [atualizada], 1996.

. Objetivos de Desenvolvimento do Milênio: Relatório Nacional de Acompanhamento. IPEA:

Brasília: $\quad$ MP, $\quad$ SPI, $2014 . \quad 208 \quad$ p. $\quad$ Disponível $\quad$ em: <http://www.pnud.org.br/Docs/5_RelatorioNacionalAcompanhamentoODM.pdf>. Acesso em 25 de fevereiro de 2017.

CRESPO, A. P. A.; GUROVITZ, E. A pobreza como um fenômeno multidimensional. RAE electron, São Paulo, v.1, n.2, p. 2 - 12, 2002. https://doi.org/10.1590/S1676-56482002000200003

HOFFMANN, R. Transferências de renda e desigualdade no Brasil (1995-2011). Programa Bolsa Família: uma década de inclusão e cidadania. Brasília: IPEA, p. 207-216, 2013.

IBGE - Instituto Brasileiro de Geografia e Estatística. Censo 2010. Disponível em: $<\mathrm{https://censo2010.ibge.gov.br/materiais/guia-do-censo/operacao-censitaria.html}$. Acesso em: $28 \mathrm{de}$ novembro de 2019.

Panorama. (s/d). Disponível em: <https://cidades.ibge.gov.br/brasil/ba/panorama>. Acesso em: 20 de novembro de 2019.

Tábua completa de mortalidade para o Brasil - 2013: Breve análise da mortalidade nos períodos 2012-2013 e 1980-2013. 2013. Disponível em : <http://ftp://ftp.ibge.gov.br/Tabuas_Completas_de_Mortalidade/Tabuas_Completas_de_Mortalidade_2 013/notastecnicas.pdf>. Acesso em: 02 de agosto de 2016.

IETS - Instituto de Estudos do Trabalho e Sociedade. Retrospectiva - Linhas de indigência e pobreza. $\quad(\mathrm{s} / \mathrm{d})$. Disponível

<http://www.iets.org.br/.../linhas_de_pobreza_e_indigencia_retrospectiva_19852013

_1415293381.xlsx>. Acesso em: 15 de agosto de 2015.

Fome e pobreza: uma relação complexa. (2011). Disponível em:

https://www.iets.org.br/spip.php?article454. Acesso em: 27 nov. 2015.

JANNUZZI, P. de M.; PINTO, A. R. Bolsa Família e seus impactos nas condições de vida da população brasileira: uma síntese dos principais achados da pesquisa de avaliação de impacto do Bolsa Família II. 2013. In: CAMPELLO, T.; NERI, M. C. (Orgs.). Programa Bolsa Família: Uma Década de Inclusão e Cidadania. Brasília, DF: IPEA.

LACERDA, F. C. C. A pobreza na Bahia sob o prisma multidimensional: uma análise baseada na abordagem das necessidades básicas e na abordagem das capacitações. 2009. 210 f. Dissertação Universidade Federal de Uberlândia (UFU), Uberlândia, 2009. 
LADERCHI, C.R.; SAITH, R.; STEWART, F. Does the definition of poverty matter? Comparing four approaches. Poverty in focus, v. 9, p. 10-11, 2006.

LIMA, A. L. M. de C. Modelagem de Equações Estruturais: uma contribuição metodológica para o estudo da pobreza. 2005. 297 f. Tese - Universidade Federal da Bahia (UFBA), Bahia, 2005.

MADRE DE DEUS (município). Informações Gerais. Prefeitura de Madre de Deus. 2015. Disponível em: <http://www.madrededeus.ba.gov.br/?page_id=117\#.Vp8ao_krLIU>. Acesso em 14 de dezembro de 2016

MEC - Ministério da Educação e Cultura. Manual de Orientação. Brasília, 2014. Disponível em: $<$ http://portal.mec.gov.br/seb/arquivos/pdf/Fundebef/manual2\%5B1\%5D.pdf>. Acesso em: 20 de janeiro de 2016.

OPHI - Oxford Poverty and Human Development Initiative. Multidimensional Poverty Index. (s/d a). Disponível em: <http://www.ophi.org.uk/wp-content/uploads/MPI-One-Page-final.pdf>. Acesso em: 03 de outubro de 2016.

How to apply Alkire e Foster. (s/d b). Disponível em: <http://www.ophi.org.uk/research/multidimensional-poverty/how-to-apply-alkire-foster/>. Acesso em: 15 de janeiro de 2017.

PNUD - Programa das Nações Unidas para o Desenvolvimento; IPEA - Instituto de Pesquisa Econômica Aplicada; FJP - Fundação João Pinheiro. Perfil dos municípios. Atlas do Desenvolvimento Humano no Brasil. 2010. Disponível em: <http://www.atlasbrasil.org.br/2013/pt/perfil_m/>. Acesso em: 15 de dezembro de 2016.

REDE INTERAGENCIAL DE INFORMAÇÕES PARA A SAÚDE. Indicadores básicos para a saúde no Brasil: conceitos e aplicações. Organização Pan-Americana da Saúde, 2002.

ROCHA, S. Alguns Aspectos Relativos à Evolução 2003-2004. 2006 da Pobreza e da Indigência no Brasil”. Revista Nova Economia, v. 11, n. 22, p. 11 - 38, 2006.

Pobreza no Brasil: afinal, de que se trata?. FGV Editora, 2003.

SANTOS, M. P. G. dos. O Estado e os problemas contemporâneos. Departamento de Ciências da Administração / UFSC. Brasília: CAPES: UAB. 144 p, 2009.

SEN, A. Desenvolvimento como Liberdade. Tradução Laura Teixeira Mota. São Paulo: Editora Schwarcz LTDA, 2010.

. Desigualdade Reexaminada. Rio de Janeiro: Record, 2001.

WAQUIL, P. D.; MATTOS, E. J. de. Distribuição de renda no Rio Grande do Sul: um comparativo entre o rural e o urbano. Ensaios FEE, v. 23, p. 621-644, 2002.

Recebido em: 18/08/2019

Aceito para publicação em: 20/02/2020 